\title{
Erratum zu „Bestimmung der Stabilität und Enantioselektivität von Lipasen“
}

\author{
ALEXANDER FULTON ${ }^{1}$, FILIP KOVACIC ${ }^{1}$, ULRICH SCHWANEBERG ${ }^{2}$, JÖRG PIETRUSZKA ${ }^{3,4}$, KARL-ERICH JAEGER ${ }^{1,4}$ \\ ${ }^{1}$ INSTITUT FÜR MOLEKULARE ENZYMTECHNOLOGIE, UNIVERSITÄT DÜSSELDORF, FORSCHUNGSZENTRUM JÜLICH GMBH \\ ${ }^{2}$ LEHRSTUHL FÜR BIOTECHNOLOGIE, RWTH AACHEN \\ ${ }^{3}$ INSTITUT FÜR BIOORGANISCHE CHEMIE, UNIVERSITÄT DÜSSELDORF, FORSCHUNGSZENTRUM JÜLICH GMBH \\ ${ }^{4}$ INSTITUT FÜR BIO- UND GEOWISSENSCHAFTEN, IBG-1: BIOTECHNOLOGIE, FORSCHUNGSZENTRUM JÜLICH GMBH
}

DOI: $10.1007 / \mathrm{s} 12268-018-0910-0$

(C) Springer-Verlag 2018

Veröffentlicht: März 2018

(c) Springer-Verlag $\mathrm{GmbH}$

DOI: 10.1007/s12268-018-0906-9

Bei der Produktion der bereits veröffentlichten Originalversion des Artikels ist ein Fehler in der Abbildung entstanden: Die Achsenbeschriftungen „Surrogatsubstrat“ und „Zuverlässigkeitsindex“ waren vertauscht. Anbei finden Sie die korrigierte Version. Wir entschuldigen uns für den Fehler und für alle dadurch eventuell entstandenen Unannehmlichkeiten.

Die Online-Version des Originalartikels finden Sie unter der DOI: 10.1007/s12268018-0906-9.

\section{Korrespondenzadresse:}

Prof. Dr. Karl-Erich Jaeger

Institut für Molekulare Enzymtechnologie

Heinrich-Heine-Universität Düsseldorf

Forschungszentrum Jülich

D-52428 Jülich

Tel.: 02461-613716

Fax: 02461-612490

k.-e.jaeger@fz-juelich.de

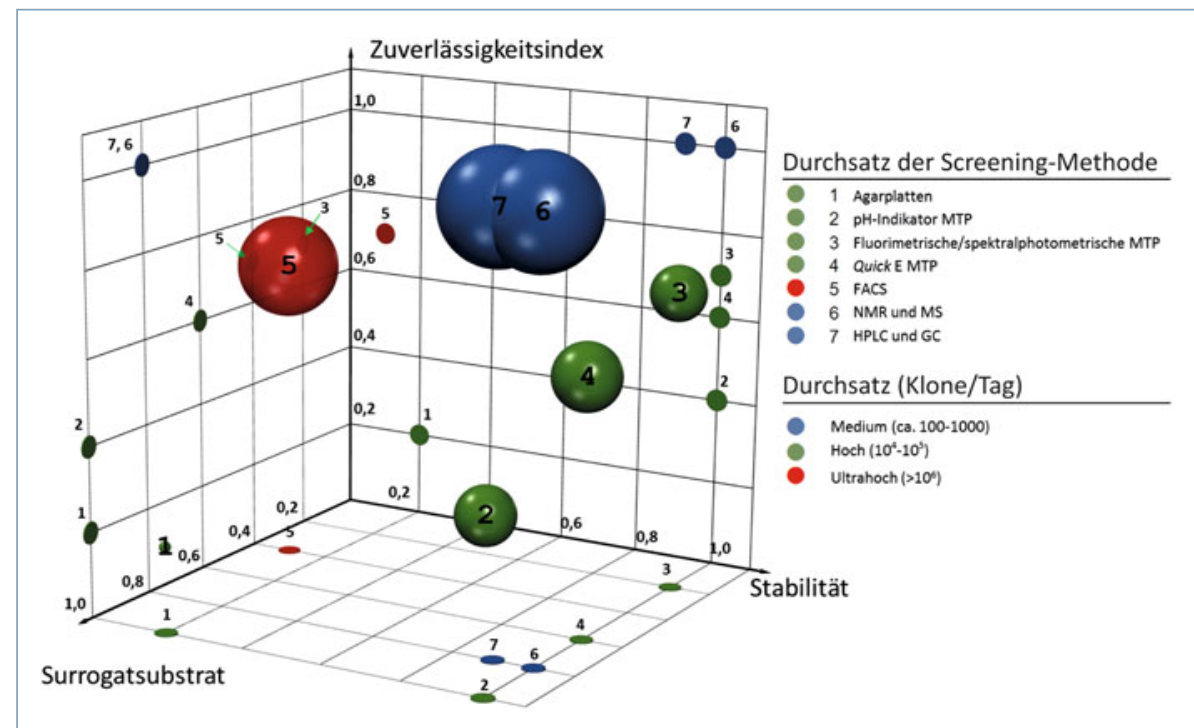

$\Delta$ Abb. 1: Parameter zur Beurteilung verschiedener Screeningmethoden zur Identifizierung von Lipasen mit erhöhter Stabilität (Temperatur, organische Lösungsmittel, Detergenzien) und Enantioselektivität. Die Größe der Kugeln ist ein Maß für die Eignung des jeweiligen Testsystems zur Bestimmung der Enantioselektivität. 